mimicry in offspring; in hybridization of races which do not naturally meet, this dominance is lost, but reasserts itself when replaced in its original genetic environment by progressive backcrossing to the race which originally possessed it.

Re-adjustment of the gene-complex under the pressure of selection will account not only for change within a species with the passage of time, but also for divergence of parts of a species. Any tondency for genes not to diffuse throughout all the members of a species will encourage the development of restricted gene-complexes. In introducing the symposium, Prof. J. Heslop-Harrison emphasized that these barriers to gene-flow, or isolating mechanisms, are of several types.

Physiological isolation by hybrid failure or sterility is the main genetic eriterion by which species status is recognized, and this may be attained at a single evolutionary step in cases of polyploidy.

Dr. R. Riley (Plant Breeding Institute, Cambridge) directed attention to the high frequency of polyploidy in plants, where successful polyploids usually arise by the combination of genomes, which, evon if derived from the same species, are sufficiently different to allow diploid behaviour (chromosome pairing) to be established at meiosis. Dr. Riley showed how cytogenetical techniques had allowed the three genomes present in common wheat, which is hexaploid, to be identified as those of Triticum monococcum, Aegilops speltoides and A. squarrosa. By taking advantage of chromosome deficiencies, the mechanism controlling genetic isolation in wheat had been located and the way opened for hybridization with other cereals.

Isolation by breeding preference was discussed by Dr. A. J. Bateman (Christie Hospital and Holt Radium Institute, Manchester). Experiments with the fly Drosophila, where a choice of mating partner is offered, indicate that, for example, body-colour mutants influence preference. Field observations of nesting pairs of birds where a plumage-colour variant is present have shown similar preference to operate in natural populations. Constaney of pollinator in plants must play a similar part as, for example, between the two campions, Silene dioica and $S$. alba, which are respectively bee- and mothpollinated.

In both outbreeding plants and animals, however, spatial isolation by ecological or geographical factors is the most widespread external mechanism which allows initial divergence either by chance restriction of genes in limited populations, or because ecological conditions differ between populations or their parts. The nature of soil preference and importance of competition were discussed by Dr. C. D. Pigott (Sheffield), who described the manner of elimination of Vaccinium vitis-idaea from mixed populations with $V$. myrtillus and occasional hybrids, by reduction in grazing pressure after enclosure and exclusion of sheep from upland oak-woods.

That divergence can precede isolation, however, is evident from experiments with Drosophila described by Dr. J. M. Thoday (Sheffield). By disruptive selection (elimination of the mean phenotypes and retention of extremes) within a single breeding population over several generations, a steady trend of divergence of the extremes is produced. Furthermore, experiments, in which the most extreme individuals are those used for breeding, demonstrate that this difference can be maintained.

Experimental studies of this type demonstrate very clearly that evolution is no longer a theory propounded by Darwin but an indisputable fact.

C. D. PigotT

\title{
OBITUARIES
}

\section{Dr. Louise Pearce}

Dr. Louise Pearce, former associate member of the Rockefeller Institute, who had worked there from 1913 until 1951, died in New York City on August 9 at the age of seventy-four years. Having graduated M.D. at the Johns Hopkins University in 1912, she began in 1913 her chemotherapeutic studies in association with $W$. H. Brown of the Institute. A few years previously Ehrlich had had great success in the treatment of disease, including syphilis, with organic arsenicals. In collaboration, these two workers studied experimentally the effect of arsenical compounds on laboratory infections in animals with the parasite causing African sleeping sickness. One compound of this series, namely tryparsamide, prepared by Jacobs and Hoidelberger in 1919 , proved very effective against rabbit syphilis and was able to save the lives of animals infected with the pathogenic African trypanosomes. Tests on the response of the human disease to this new substance were now urgently required. Louise Pearce, of resolute character and endowed besides with great physical strength and vigour, was chosen to go out to the Belgian Congo in 1920, where thousands of natives were dying of the disease, and there carried out the tests at great personal risk.

The success of the new drug was soon obvious and, as Peyton Rous has written, "she brought about one of the most shining and spectacular of the early purposeful achievements of the Institute, the conquest of sleeping sickness". Tryparsamide owes its importance to the fact that it can reach the cerebrospinal fluid in considerable concentration and has the capacity to affect trypanosomes in the central nervous system. For this work Dr. Pearce was awarded in 1953 the King Leopold II prize of 10,000 dollars and made an officer of the Royal Order of the Lion, having previously received the Belgian Order of the Crown. Her colleagues, W. A. Jacobs, M. Heidelberger and W. H. Brown, were also honoured. With the last-named she discovered a rabbit cancer, known as the Brown-Pearce carcinoma, which could be transplanted to other rabbits and has proved of considerable value experimentally. The virus causing rabbit pox was another of her discoveries.

She was keenly interested in medical education and served during $1946-51$ as president of the Women's Medical College of Philadelphia. Besides her successful mission to Africa she served as visiting professor of medicine at leiping Union Medical College during 1931-32. Her interests were wide and embraced many aspects of national and international life. As an officer of a number of organizations concerned with the study of bacteriology, medicine, tropical medicine, eancer and other diseases, she proved a good citizen of the world. 
During her life-time she was awarded a number of honorary degrees and prizes. Her monograph "The Treatment of Human Trypanosomiasis with Tryparsamide", published by the Rockefeller Institute, is a classic.

J. D. FultoN

\section{Dr. E. S. Duthie}

Dr. Edward Stephens Duthie died on June 9 at the age of fifty-two. He was an experimental and clinical pathologist with an exceptional range of talents. Born in Kilkenny, he won a sizarship in mathematics to Trinity College, Dublin, and graduated in arts, medicine and science. He began biological research under Prof. J. B. Gatenby in Dublin and continued under Prof. A. E. Boycott at University College Medical School, London, where he went as Graham Scholar in 1933. His published work during this period was concerned mainly with the mechanism of glandular secretion. While convalescing from tuberculous pleurisy in Italy he wrote a paper on the origin, development and function of the blood cells in certain marine teleosts.

After a brief interlude as assistant pathologist at the University of Sheffield, he joined the staff of the Dunn School of Pathology, Oxford, and collaborated with Chain in a study of 'spreading factor', which they identified as hyaluronidase. Duthie was unfit for military service during the War so he worked as hospital pathologist at Northampton until he was recalled to Oxford to help Sir Hugh Cairns; he organized and took charge of all the chemotherapy at the Radcliffe Infirmary and at the Military Hospital for Head Injuries. His development of penicillinase, his work with Chain on the theory of action of penicillin and his demonstration of the influence of $p H$ on the activity of streptomycin, have all contributed to the rapid progress of chemotherapy.

Duthie took charge of the Serum Department of the Lister Institute in London in 1946 and worked on serum and bacterial proteases and their inhibitors. In 1948 he was appointed deputy director of pathology at Southampton, becoming director in 1952. During the past ten years he studied various products of the staphylococeus. His crowning achievement was the purification of coagulase-the first blood-clotting substance to be purified.

Duthie's integrity, sympathy and kindness were apparent to all who met him; his friends knew his generosity, his concern for refugees and all who were oppressed, his appreciation of art and music and his courage and cheerfulness in the face of prolonged ill-health.

Charles H. Lack

\section{Mr. John Cecil May, C.M.G., O.B.E.}

Bx the death on September 10 of J. C. May, director of the Empire Cotton Growing Corporation, tropical agriculture has lost one of its wisest and most distinguished administrators of agricultural research. His background of geology and forestry at Oxford, and of the administrative service in Nyasaland and Tanganyika, was singularly appropriate for the development of his life's work in an independent corporation engaged in research in tropical territories. His judgment and enthusiasm were largely responsible for the high standard of recruitment to the Corporation's service, and his sympathy and understanding for the welfare of his staff in the diverse circumstances in which they work. He understood the needs and difficulties as well as the responsibilities of government departments, and his breadth of interest was the foundation of the co-operation between government officials and the research staff of the Corporation that has been so fruitful in the extension of the cotton crop in African territories. His vision and grasp of practical needs and possibilities enabled the Corporation to continue to provide staff for the Sudan when the Republic of the Sudan was established. In planning the British contribution to technical services in the new Africa that is emerging, his counsel will be sorely missed.

\section{J. B. HUTCHINSON}

\section{NEWS and VIEWS}

\section{International Red Locust Control Service}

The last plague of the red locust, Nomadacris septemfasciata Serville, lasted from 1930 until 1944 and affected most of Africa south of the equator. Field investigations by British, South African and Belgian scientists revealed comparatively small outbreak areas in Northern Rhodesia and Tanganyika. In 1941 A. P. G. Michalmore set up headquarters in Abercorn, Northern Rhodesia, and began preventive control of these areas; in $1945 \mathrm{H}$. J. Bredo became director of the International Red Locust Control Service. This Service was established by international treaty in 1949 and the first decade of the treaty was completed on August 5 this year. At first, the idea was to watch for any upsurge of locusts in the outbreak arcas and then to arrange control measures, but it became clear that events moved too quickly and the Service had to be constantly ready to attack. Even so, swarms escaped from the outbreak areas in most years until operational research, mainly by Haydn Lloyd, led to the design of fully effective methods of control, using very light aircraft. In 1955 there occurred the largest upsurge ever recorded ; it was completely controlled. No swarms have escaped since 1954 .

Dr. D. L. Gunn, C.B.E.

DURING the period 1952-59 the director of the International Red Locust Control Service was Dr. D. L. Gunn. Educated at the High School and the University College, Cardiff, he was then for seventeen years at the University of Birmingham, first as assistant lecturer and finally senior lecturer in zoology. There he became known for researches on the temperature and humidity relations of insects and he collaborated with Dr. Gottfried Fraenkel in "The Orientation of Animals" (Oxf. Univ. Press). Towards the end of the War, he was seconded to Kenya to study the behaviour of desert locusts in swarms, in relation to aircraft spraying, and in $\mathbf{1 9 4 5}$ with Douglas Yeo and a team from the Chemical Defence Experimental Establishment, Porton, he carried out the first attacks on adult locusts in Africa that used liquid insecticide sprayed from aireraft. In 1946 he became the first principal scientific officer of the Anti-Locust Research Centre, then newly separated, under Dr. B. P. Uvarov, from the Common- 